\title{
O USO DE CHARGES E HISTÓRIAS EM QUADRINHOS PARA POTENCIALIZAR A EDUCAÇÃO AMBIENTAL NO ENSINO DE CIÊNCIAS
}

\author{
Leonardo Priamo Tonello1; Tamini Wyzykowsk²; Roque Ismael da Costa Güllich ${ }^{3}$
}

\section{RESUMO}

O presente relato faz uma análise e reflexão sobre uma prática pedagógica de Educação Ambiental (EA) envolvendo a utilização de charges e quadrinhos. A ação foi realizada em duas turmas de $6^{\circ}$ ano do Ensino Fundamental, na disciplina de Ciências, em uma escola pública do município de Cerro Largo, Estado do Rio Grande do Sul (RS), Brasil (BR). A atividade consistiu em um debate sobre algumas problemáticas ambientais, que foram trabalhadas com 0 uso de charges e quadrinhos. Nas escritas registradas pelos alunos, há indícios que os estudantes desenvolveram um pensamento crítico e uma sensibilização sobre as questões ambientais que foram discutidas em sala de aula. Os resultados evidenciam o potencial das charges e quadrinhos para promover a EA e mediar aprendizagens no ensino de Ciências.

Palavras-chave: Pensamento crítico; Problemáticas ambientais; Sensibilização.

\section{THE USE OF CARTOONS AND COMICS TO ENHANCE ENVIRONMENTAL EDUCATION IN SCIENCE TEACHING}

\section{ABSTRACT}

The present account analyzes and reflects a teaching practice in Environmental Education (EE) using editorial cartoons and comic strips. The action occurred in two 6th grade classes of middle school, in the subject of Science, in a public school in Cerro Largo, Rio Grande do Sul (RS), Brazil (BR). The activity constituted in a debate on some environmental issues, which were approached with editorial cartoons and comic strips. In the students' writing registers, there is evidence that they developed their critical thinking and raised their awareness of environmental issues that had been discussed in the classroom. The results highlight the potential of editorial cartoons and comic strips in promoting EE and in mediating learning in Science teaching.

1 Acadêmico de Ciências Biológicas - Licenciatura. Universidade Federal da Fronteira Sul (UFFS), Campus Cerro Largo. Bolsista PETCiências, do Programa de Educação Tutorial - PET (SESu/MEC/FNDE). E-mail: leonardo.priamo.tonello@gmail.com.

2 Mestre e Doutoranda em Educação nas Ciências. Universidade Regional do Noroeste do Estado do Rio Grande do Sul (UNIJUÍ). Bolsista da Coordenação de Aperfeiçoamento de Pessoal de Nível Superior (CAPES). E-mail: tamini.wyzykowski@gmail.com.

3 Doutor em Educação nas Ciências. Professor Adjunto de Prática de Ensino, Tutor do PetCiências- FNDE-MEC/UFFS, Pesquisador Líder do GEPECIEM, Licenciatura em Ciências Biológicas, UFFS. E-mail: bioroque.girua@gmail.com. 
Keywords: Critical thinking; Environmental issues; Awareness.

\section{Introdução}

No Brasil, há uma série de esforços para estabelecer a Educação Ambiental (EA) como uma disciplina do currículo na Educação Básica. Em 1988, a Constituição Federal4 instituiu a obrigatoriedade da abordagem da EA em todos os níveis de ensino. Nos Parâmetros Curriculares Nacionais (PCN) ela aparece principalmente nas discussões sobre Meio Ambiente, que é um tema transversal e possível de ser trabalhado em todas as áreas do conhecimento (BRASIL, 1997). A Educação Ambiental é vital para a formação humana e cidadã de toda sociedade.

Ao encontro disso, Sauvé (2005) aponta para a importância de analisar e compreender a origem dos problemas socioambientais contemporâneos, a fim de zelar por uma boa relação entre o homem e a natureza. Assumimos junto ao autor, a ideia de que é fundamental o homem se reconhecer como parte do meio ambiente e assumir essa perspectiva de pertencimento e integração. Pensando na educação escolar, isto implica na necessidade de formar cidadãos com um pensamento crítico.

O ensino de Ciências possibilita importantes contribuições no que diz respeito a promoção da EA. Para tanto, as temáticas ambientais tratadas devem ser contextualizadas conforme a realidade dos estudantes, considerando a dimensão global dos problemas discutidos em sala de aula, sem ignorar possíveis influências de relações de poder e interesses que podem estar neles implícitos.

A EA é um meio de sensibilizar os estudantes e orientá-los para o despertar de um pensamento de pertencimento e integração entre sociedade e meio ambiente, desenvolvendo a emancipação da consciência ambiental. Segundo Carvalho (2004), a EA é fundamentada pela configuração de

4 Art. 225. Todos têm direito ao meio ambiente ecologicamente equilibrado, bem de uso comum do povo e essencial à sadia qualidade de vida, impondo-se ao Poder Público e à coletividade o dever de defendê-lo e preservá-lo para as presentes e futuras gerações. $\S 1{ }^{\circ}$ Para assegurar a efetividade desse direito, incumbe ao Poder Público: VI- promover a educação ambiental em todos os níveis de ensino e a conscientização pública para a preservação 
propostas formativas, embasadas na perspectiva de promover uma educação integral e cidadã do sujeito, viabilizando a significação de valores, transformando atitudes e levando-o a assumir uma postura responsiva perante as questões ambientais.

Seguindo essa linha de pensamento, é imprescindível refletir sobre como ocorre a problematização da EA durante as ações pedagógicas propostas nos contextos escolares. Nesse sentido, vale referir que o trabalho do professor é determinante para a significação dos conhecimentos culturais que estão imbricados na EA. Concordamos com o pressuposto de Zeichner (2008, p. 545), ao argumentar que "se os professores refletirem sobre o que fazem, eles necessariamente serão melhores profissionais".

Cachapuz et al. (2005), alertam que as concepções docentes orientam as práticas pedagógicas, que por sua vez, em alguns casos ainda podem estar focadas na transmissão linear de conteúdos, ou limitando-se à transmissão de verdades da Ciência. Segundo os mesmos autores, "isto não só deixa na sombra as características essenciais da atividade científica e tecnológica, senão que contribui a reforçar algumas deformações, como o suposto caráter 'exacto' (ergo dogmático) da ciência, ou da visão a problemática” (ibdem, p. 53).

Partindo disto, socializamos neste texto reflexões e entendimentos sobre a realização de uma prática pedagógica no ensino de Ciências, que enfatizava o uso de charges e quadrinhos para debater a EA no contexto escolar.

Destacamos que as histórias e quadrinhos são caracterizadas por uma linguagem que apresenta textos, códigos e imagens. Estes elementos estabelecem a comunicação com o leitor e no ensino, com a intermediação do professor, podem potencializar aprendizagens de EA, ao passo que instigam discussões e o delineamento de interpretações (NETO; SILVA, 2011; RAMOS, 2014; VERGUEIRO, 2014). A utilização de histórias e quadrinhos podem integrar grupos de debates, assim como rodas de conversa, pois convidam à participação coletiva sobre um determinado tema, que vai resultar em um processo de construção e transformação de ideias, facilitando a troca de experiências de forma contextualizada (SILVA et al., 2007).

Nesta escrita, visamos um olhar investigativo sobre uma prática 
vivenciada no ensino de Ciências, buscando apreender como a utilização de charges e quadrinhos pode contribuir para o desencadeamento de discussões de EA e para a formação crítica dos alunos. A partir da análise de alguns relatos dos estudantes participantes, temos 0 intuito de sistematizar compreensões de dimensões formativas da EA, construídas no percurso das ações empreendidas no nosso contexto.

\section{O contexto e a metodologia}

A prática pedagógica envolvendo EA que apresentamos neste relato foi realizada com duas turmas de $6^{\circ}$ ano do Ensino Fundamental, na disciplina de Ciências, em uma escola pública do município de Cerro Largo, Estado do Rio Grande do Sul (RS), Brasil (BR).

A atividade, consistiu em um debate sobre questões relacionadas com a EA, utilizando para tanto charges e quadrinhos, que continham em seu conteúdo alguma abordagem ambiental. As temáticas estavam explícitas ou implícitas nas charges e nos quadrinhos, sendo assim, os alunos precisavam observar e debater a respeito do material e identificar o que o conteúdo estava problematizando. As charges e quadrinhos, que foram selecionadas previamente, tratavam de implicações ambientais, sociais, econômicas e, bem como, algumas possíveis soluções. A figura 1 é um exemplo do material utilizado com os alunos. 
Figura 1: Charges/quadrinhos, trabalhados no Ensino de Ciências com EA.

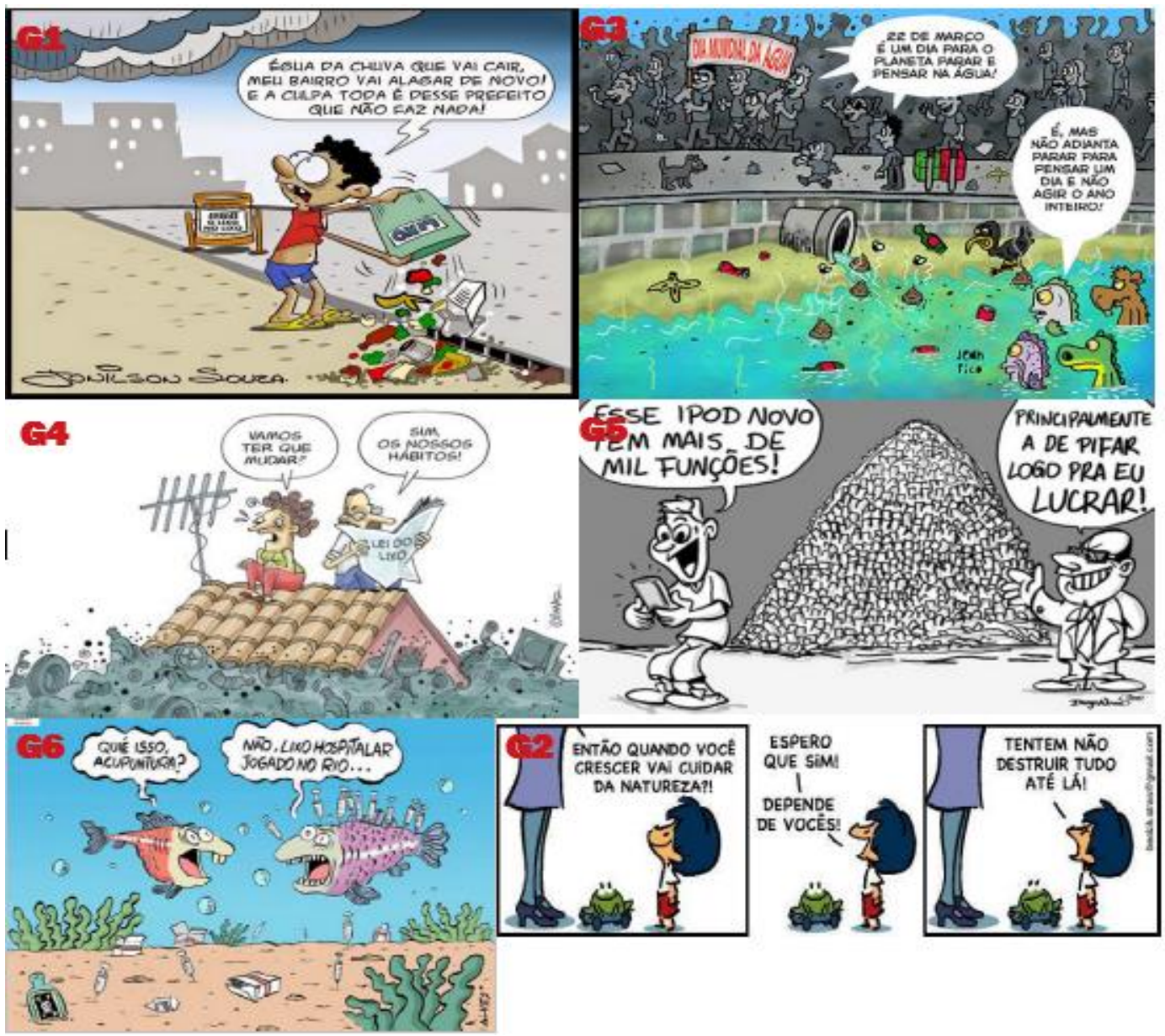

Fonte: Adaptado de Google Imagens.

Para desenvolver a prática pedagógica de EA, inicialmente os alunos foram divididos em grupos de quatro pessoas. Foram formados seis grupos nas turmas A e B, pois ambas continham 24 alunos. Cada grupo recebeu uma charge ou quadrinho, impresso e colorido em folha A4, conforme exemplificamos com a (Figura 1). Os grupos foram orientados a discutir e registrar por escrito seus entendimentos em relação à leitura da charge ou quadrinho recebido. Em seguida, os estudantes foram convidados a socializar suas compreensões com toda a turma, a fim de se instituir um momento de interação, reflexão e partilha de conhecimentos. A atividade teve duração de duas horas-aula. Ao final, os grupos entregaram as descrições produzidas à professora de Ciências para posterior avaliação.

A sistematização do presente relato, se deu a partir da análise das escritas produzidas pelos grupos de alunos, inseridos nesta prática pedagógica com charges e quadrinhos. Nos excertos de escritas dos estudantes, que em 
seguida serão apresentados, buscamos (re) conhecer suas impressões tangentes à EA. Para discutir os resultados e manter o anonimato dos sujeitos envolvidos, utilizamos alguns descritores, sendo eles: TA e TB, para nomear as turmas A e B; e G1, G2, G3, G4, G5 e G6 para identificar os seis grupos. No texto, agrupamos os descritores das turmas com os descritores dos grupos: TAG1; TBG1; TAG2; TBG2... sucessivamente até o TBG6.

Cabe explicitar que a prática pedagógica de EA no Ensino Básico que estamos analisando foi mediada pela professora de Ciências em trabalho colaborativo com bolsistas do Programa de Educação Tutorial em Ciências (PETCiências), da Universidade Federal da Fronteira Sul (UFFS), Campus Cerro Largo - RS. O PETCiências é um programa que visa qualificar a formação inicial em Ciências, articulando a interdisciplinaridade e o desenvolvimento de atividades na tríade de ensino, pesquisa e extensão. Ele tem como temática central "Meio Ambiente e Formação de Professores". Entre outras ações, o programa possibilita aos licenciandos dos cursos de Licenciatura em Ciências Biológicas, Física e Química da UFFS, inseridos como bolsistas, a realização de atividades de iniciação a docência nas escolas de Escola Básica. Deste modo, os futuros professores têm a oportunidade de atuar no Ensino de Ciências, familiarizando-se com o ambiente escolar e participando de um processo de formação mútua, entre licenciandos, professores de Educação Básica e estudantes de nível Fundamental e Médio.

\section{Resultados e discussões}

A EA é fundamental na formação do sujeito e para o desenvolvimento da humanidade. Nesse sentido, sua abordagem não deveria se limitar às aulas expositivas ou pouco atraentes para os estudantes. A EA precisa ser planejada transversalmente, de modo que problematize e provoque transformações nas concepções, comportamentos e hábitos dos alunos (NOGUEIRA, 2002).

Ao considerarmos o cerne da questão transversal em sala de aula, convém destacar a necessidade do professor pensar em atividades de EA contextualizadas, que viabilizem a aprendizagem de conhecimentos teóricos e históricos, que estão imbricados em questões ambientais contemporâneas. Temos que considerar que as práticas pedagógicas são determinantes para a 
significação da EA, e sendo assim, devem primar por possibilitar e conduzir os sujeitos que ocupam os bancos escolares para "o despertar de uma sociedademundo" (MORIN et al. 2007, p. 63).

Contudo, vale referir que a transversalidade da EA, nem sempre é compreendida e desenvolvida deste modo pelos professores. Em alguns casos, ela ocorre subordinada pelo conhecimento compartimentalizado, ou por uma abordagem fragmentada (YUS, 1998).

$\mathrm{Na}$ condição de professores, é nosso papel discutir a EA em nossos campos de atuação profissional, de modo que tais discussões atuem como elemento de reflexão e sensibilização nos alunos, capaz de transformar hábitos e instigar o pensamento crítico em relação aos problemas do meio ambiente, contribuindo de algum modo "para com a vida e um sentimento de pertença amorosa à Mãe-Terra" (BOFF, 2008, p. 26).

É fundamental que o professor planeje suas aulas utilizando metodologias de ensino capazes de conduzir os alunos a estabelecer relações sob diferentes dimensões de mundo, ambiente e sujeito, em consonância com o processo educativo, construindo, reconstruindo e transformando-o (YUS, 2002). Nesta perspectiva, o uso de charges e quadrinhos surge, na possibilidade de uma leitura comunicativa sobre as problemáticas ambientais e os demais elementos constituintes destas, pois organizam-se em uma profunda ilustração, embasada no teor crítico, sobre um tema, espaço e tempo (NETO; SILVA, 2011; RAMOS, 2014).

Nas descrições dos grupos que realizaram a prática com charges e quadrinhos, identificamos indícios de que os alunos desenvolveram um pensamento crítico a respeito das questões ambientais problematizadas em sala de aula. Essas impressões podem ser evidenciadas quando os estudantes expressam que "[... ${ }^{5}$ devemos ser responsáveis pelo nosso lixo" (TAG3), que "deve-se pensar em uma nova consciência com o lixo hospitalar, ainda mais por se tratar de algo tão particular e perigoso" (TAG6) e, ainda, na conclusão de que “...não pensamos no descarte, nos problemas que

5 Os trechos de escritas de até três linhas foram utilizados no corpo do texto. Os excertos com mais de três linhas foram dispostos com recuo de $4 \mathrm{~cm}$. Todos os depoimentos estão com destaque tipográfico entre aspas e em itálico, sendo que em negrito destacamos as ideias centrais. Realizamos algumas correções linguísticas e de ortografia parcial das escritas, para não descaracterizar o contexto. 
podem causar, apenas consumimos cada vez mais e mais" (TBG5). Na mesma linha de pensamento, também se encaminham os seguintes depoimentos:

\begin{abstract}
"comemoramos muito e fazemos pouco, não adianta lembrar de um dia importante se não termos boas ações durante o ano e no nosso dia a dia. A água vem cada vez mais sendo poluída e em vez das pessoas preservarem, acabam poluindo mais, o que acreditamos que poderá faltar futuramente. 0 que será depois, não teremos mais água? Essa pergunta todos deveriam fazer e se preocupar. Lembrar é importante, mas agir também!" (TBG3);

"De quem é a culpa do mundo estar assim? A resposta é simples e se chama HUMANIDADE. Muitos dos seres humanos não respeitam a natureza, bem é só jogar um lixo no chão $e, \ldots$ já foi poluído, as vezes esse lixo demora décadas, séculos ou milênios para se decompor, o que não é bom e se cada um jogar apenas 1 ou 2 lixo vai virar um lixão. Muitos de nós não percebemos que pouco a pouco o planeta está se destruindo por causa das pessoas, alguns tentam achar soluções e outros poluem os rios, lagos, não separando o lixo (seco, úmido...). A humanidade se refere aos humanos, sendo assim eu, você e todos nós juntos, poluímos sem mesmo perceber e que com simples atos comuns, como não separar o lixo, jogar o lixo no chão por preguiça de ir até a lixeira, etc. Adultos já são responsáveis e deveriam saber disso, e deveriam se preocupar com seus filhos, seus netos precisão de um planeta para morar. $O$ que falta é CONSCIÊNCIA, sim isso ai, se não pensar várias vezes, não sabe o que pode acontecer com o planeta" (TBG2).
\end{abstract}

Os excertos apresentados parecem evidenciar que os estudantes desenvolveram uma sensibilização ambiental frente as questões que foram trabalhadas em sala de aula. Com isso e apoiados em Guimarães (2009), compreendemos que a inserção da EA no Ensino de Ciências propicia momentos de aprendizagens e de formação humana e cidadã. É pertinente recorrer a propostas pedagógicas que estimulem a reflexão e o debate de temas relacionados a ciência, ao meio ambiente e a sociedade, que podem ter potencialidades e contribuições no âmbito da EA.

Nas escritas analisadas, percebemos que os sujeitos envolvidos possuíam traços de uma consciência ambiental: "o menino estava jogando lixo em um lugar não adequado [...]. Ele não se dá em conta que está fazendo errado" (TBG1). Durante o desenvolvimento da atividade proposta, os alunos se reconheceram como autores e atores da sociedade que pertencem, como pode ser depreendido na seguinte manifestação: "uma ação individual afeta a todos do bairro, portanto todos devem cuidar" (TAG1). Com isso, destacamos a importância da EA nos espaços escolares a fim de possibilitar aos alunos uma visão global e crítica de sociedade, que tende a provocar um 
sentimento de pertencimento, responsabilidade e a ideia de coletividade em relação ao cuidado da natureza: “...isso é para todos. Todos podem ajudar o meio ambiente (TAG2).

Vale refletir que, em alguns casos, trabalhar a EA pode se caracterizar como um desafio, especialmente pela necessidade do professor construir um elo entre as transformações científicas e tecnológicas e às questões ambientais presentes no cotidiano dos alunos. A EA precisa ser contextualizada para produzir sentidos e significados no ensino de Ciências. Isso exige do professor o domínio conceitual das temáticas de EA e que ele também leve em conta os saberes prévios dos alunos, para que os conhecimentos cotidianos se transformem em conhecimentos científicos escolares. Maldaner e Zanon (2004) discorrem que "que temos de avançar para que as vivências e opiniões que os estudantes trazem para a sala de aula, ou seja, os conhecimentos provenientes do 'senso comum', ou da sua realidade social, sejam empregados para a compreensão dos conceitos científicos" (p. 52).

Com base nos pressupostos dos autores, defendemos a necessidade de uma ação educativa que promova a EA no sentido de contribuir no desenvolvimento de sujeitos críticos e responsáveis frente a sociedade e ao meio ambiente. Entendemos que na escola a EA deve ser capaz de sensibilizar os alunos e despertar um sentimento de pertencimento coletivo, considerando a opinião ou pensamento individual de cada sujeito, direcionando-os a "compreender a vida como consequência da história da Terra e a humanidade como consequência da história da vida na Terra" (MORIN, 2002, p. 63).

Pelas descrições elaboradas e considerando as discussões que ocorrem na turma, interpretamos que foi positivo o uso de charges e quadrinhos para promover a significação e apropriação de conhecimentos de EA junto aos alunos. Nas sistematizações, os grupos discutiram sobre a necessidade de uma transformação social e ambiental. Na visão deles: “...a tecnologia, todo mundo quer! Mas quando compra... bota fora o velho, que vai para o lixo!" (TAG5); “...um exemplo, são nossos celulares estragados e vários lixos eletrônicos, que vão para o meio ambiente, que resulta na poluição" (TBG5). Os estudantes também associaram a evolução da tecnologia e da ciência no enredo da preocupação ambiental, isso é revelado quando um dos grupos infere: "as criações e inovações humanas poluem o ambiente, como 
produtos químicos que são altamente tóxicos, despejados todos os anos pelos esgotos, quase todos tem destino em rios e lagos, como em alguns rios da nossa cidade e do meio rural, pelos agrotóxicos" (TBG2).

Os relatos são um convite à reflexão de que a inserção de discussões de EA em contextos formativos viabiliza ao aluno analisar os acontecimentos que ocorrem em seu meio social, remetendo, quando necessário, à mudança de posturas frente as questões ambientais. Devido a estes aspectos, acreditamos no potencial da abordagem de EA pelo viés de charges e quadrinhos em sala de aula. Esses recursos pedagógicos viabilizam a realização de grupos de trabalho e instigam a participação dos estudantes, que refletindo sobre o tema em destaque, acabam construindo momentos de "conflitos" de argumentação e debates contextualizados sobre as temáticas ambientais abrangentes (SILVA et al., 2007).

Vale observar que os elementos de linguagem que compõem as charges e quadrinhos costumam ser de fácil leitura e interpretação, permitindo aos alunos elencar os problemas sociais que assolam seu enredo e compreender a razão de tal fenômeno. Podemos observar esses aspectos na seguinte descrição sobre uma charge: "fala sobre a poluição de rios e mares: pode ocorrer morte a vários animais, nós e de seres vivos que bebem a água contaminada" (TAG6). No contexto deste relato, o material utilizado continha elementos da natureza nas ilustrações, que integravam junto aos enredos enunciados uma ideia de mutualidade dos seres vivos com o ambiente natural: "o tema da charge é que não devemos jogar o lixo nas águas, mares, rios...nos ensinou que prejudica os peixes e os demais seres vivos que também vivem nela" (TAG3).

Os depoimentos dos estudantes reforçam a ideia de que as charges $e$ quadrinhos são um recurso favorável para ensinar Ciências e fomentar a EA, conscientizando os alunos que "devemos cuidar das águas, os animais também precisam dela (TBG3) e sensibilizando-os: "muitos animais são prejudicados com esta água e acabam morrendo intoxicados pela irresponsabilidade humana, este foi apenas um exemplo de muitos tipos de poluições que geram a irresponsabilidade das pessoas" (TBG2).

Reiteramos que a EA, a partir disso, também envolve a relação de meio ambiente, saúde e qualidade de vida. Em alguns relatos, notamos que as 
condições de saúde e ambiente foram esboçadas com uma ideia de integração e dependência uma da outra, conforme foi associado pelo grupo: "devemos reciclar o lixo e não jogar em qualquer lugar, pois pode chegar até as águas e prejudicar a saúde das pessoas. Isso é um caso de saúde pública" (TAG3).

O contexto da prática pedagógica evidencia que as charges e quadrinhos contribuíram para significação de alguns entendimentos de EA nas aulas de Ciências. As escritas realçam vestígios de pensamento crítico dos sujeitos sobre as temáticas socioambientais debatidas: ciência e tecnologia, relação homem-natureza, saúde, meio ambiente, bem-estar e qualidade de vida. Com isso, destacamos a EA como um mecanismo substancial de constituição humana e transformação social.

\section{Algumas considerações}

A partir da prática desenvolvida e analisada neste relato, destacamos 0 potencial de metologias e propostas educativas com o uso de charges e quadrinhos para desenvolver a EA no ensino de Ciências. Os relatos produzidos pelos estudantes retratam esta atividade como uma possibilidade para promover a sensibilização ambiental, a transformação de concepções da relação meio ambiente e sociedade, bem como fundamentar discussões sobre saúde e qualidade de vida. Também convém ressaltar, que propostas deste cunho pedagógico permitem romper com o ensino linear e sistemático, acentuando o olhar crítico dos alunos sobre as questões contemporâneas de seu tempo-espaço social.

Identificamos a partir dos relatos a importância dos sujeitos produzirem entendimentos sobre de EA, pois isso vai mobilizá-los à reflexão dos seus atos e à transformação da sua conduta cidadã. Depreendemos que quando o sujeito se sente integrado e se identifica como pertencente ao meio ambiente, este é capaz de dimensionar e interligar variadas temáticas ambientais, suas causas, efeitos e soluções. Ademais, a sensibilização ambiental leva à compreensão de que cada ação individual tem uma proporção relevante na coletividade.

Reiteramos ainda, que é imprescindível cogitar na indissociabilidade da EA com a realidade dos estudantes. As propostas formativas de EA tem de considerar o contexto social, bem como os conhecimentos prévios dos alunos sobre as questões ambientais presentes em seu meio. É papel da escola 
oferecer condições para que os sujeitos sejam capazes de ler, interpretar e se movimentar no mundo.

Por fim, pontuamos a necessidade de se intensificar as discussões de EA nos cursos de formativos de professores, tanto na formação inicial quanto na formação continuada. O professor é o intermediador do processo educativo escolar e tem um papel primordial na construção de práticas pedagógicas, que oportunizem a aprendizagem de conhecimentos científicos escolares, a formação humana dos sujeitos e o tratamento contextualizado da EA no ensino de Ciências.

\section{Referências}

BRASIL. Secretaria de Educação Fundamental. Parâmetros Curriculares Nacionais: meio ambiente, saúde. Brasília, 1997.

BRASIL. Constituição da República Federativa do Brasil. 1988.

BOFF, Leonardo. Saber cuidar: ética do humano, compaixão pela terra. 14. ed. Petrópolis: Vozes, 2008.

CACHAPUZ, Antonio et. al. A necessária renovação do ensino das ciências. São Paulo: Cortez, 2005.

CARVALHO, Isabel Cristina de Moura. Educação ambiental crítica: nomes e endereçamentos da educação. In: MMA/ Secretaria Executiva/ Diretoria de Educação Ambiental (Org.). Identidades da educação ambiental brasileira. Brasília: MMA, 2004.

GUIMARÃES, Luciana Ribeiro. Atividades para Aulas de Ciências. 1 ed. São Paulo: Nova Espiral, 2009.

MALDANER, Otávio Aloísio; ZANON, Lenir Basso. Situação de Estudo - Uma organização do ensino que extrapola a formação disciplinar em Ciências. In: MORAES, Roque; MANCUSO, Ronaldo. Educação em Ciências-Produção de currículos e formação de professores. ljuí: Ed. Unijuí, 2004.

MORIN. Edgar, Ciência com consciência. 6. edição. Trad. Maria D. Alexandre e Maria Alice S. Dória. RJ: Bertrand Brasil, 2002.

MORIN, Edgar; CIURANA, Emilio-Roger; MOTTA, Raúl Domingo. Educar na era planetária: o pensamento complexo como método de aprendizagem pelo erro e incerteza humana. Trad. Sandra Tabuco Valenzuela. $2^{\underline{a}}$ ed. São Paulo: Cortez; Brasília: UNESCO, 2007. 
MORAES, Roque; LIMA, Valderez Marina do Rosário. Pesquisa em sala de aula: tendências para a educação em novos tempos (orgs.). Porto Alegre: EDIPUCRS, 2002.

NOGUEIRA, Nilbo Ribeiro. Temas Transversais: reflexões e práticas rumo a uma nova educação. São Paulo: Érika, 2002.

RAMOS, Paulo Eduardo. A leitura dos quadrinhos. 2a ed. São Paulo: Contexto, 2014.

NETO, Elydio dos Santos; SILVA, Marta Regina Paulo da (Org.). Histórias em Quadrinhos \& Educação: formação e prática docente. São Bernardo do Campo: Universidade Metodista de São Paulo, 2011.

SAUVÉ, Lucie. Educação Ambiental: possibilidades e limitações. Educação e Pesquisa, v. 31. n.2. p. 317-322, 2005.

SILVA, Petronilha Beatriz Gonçalves e; GUAZZELLI, Nara Maria Bernardes. Rodas de Conversas - Excelência acadêmica é a diversidade. Educação, v. 30, n. 1, p. 53-92, jan./mar. 2007.

VERGUEIRO, Waldomiro. A linguagem dos quadrinhos: uma "alfabetização" necessária. In: RAMA, Angela; VERGUEIRO, Waldomiro (Org.). Como usar as histórias em quadrinhos na sala de aula. 4. ed. São Paulo: Contexto, 2014, p. 31-64.

YUS, Rafael. Temas transversais: em busca de uma nova escola. Porto Alegre: Artmed, 1998.

YUS, Rafael. Educação integral: uma educação holística para o século XXI. Porto Alegre: Artemed, 2002.

ZEICHNER, Kenneth M. Uma análise crítica sobre a "reflexão" como conceito estruturante na formação docente. Educação e Sociedade, vol. 29, n. 103, p. 535-554, mai/ago, 2008. 